Indonesian Journal of Biotechnology, June, 2014

Vol. 19, No. 1, pp.91-98

\title{
Histological Features of Catecholaminergic Neuron in Substantia Nigra Induced by Paraquat Dichloride (1,1-dimethyl-4,4 bipyridinium) in Wistar Rat as A Model of Parkinson Disease
}

\author{
Tri Wahyu Pangestiningsih ${ }^{1 *}$, Woro Danur Wendo ${ }^{1}$, Yulfia Nelymalik Selan², Filphin \\ Adolfin Amalo ${ }^{2}$, Nemay Anggadewi Ndaong ${ }^{3}$, Victor Lenda ${ }^{4}$
}

\author{
${ }^{1}$ Department of Anatomy, Faculty of Veterinary Medicine, Gadjah Mada University, Yogyakarta \\ ${ }^{2}$ Department of Anatomy, Nusa Cendana University, Kupang \\ ${ }^{3}$ Department of Pharmacology, Nusa Cendana University, Kupang \\ ${ }^{4}$ State Agriculture Politechnic, Kupang
}

\begin{abstract}
Paraquat dichloride has been used by farmers as a herbicide to kill the grass. On the other hand, paraquat dichloride is harmful if enters to the body, causing Parkinson's disease, since it is disrupting dopamine production in the substantia nigra pars compacta or dopamine pathways Nigro striatal pathway. The study was done to find out the histological changes of catecholaminergic neurons and Nigro striatal pathway caused by paraquat dichloride treatment in Wistar rats as a model of Parkinson's disease.

Twenty-two Wistar rats 3,5 months old were divided into 4 groups, 5 rats each. Group I (control group) were injected with aquabidest, while groups II, III, and IV were injected intraperitoneally with paraquat dichloride in aquabidest, with the dosage 5,10 and $15 \mathrm{mg} / \mathrm{kg}$ bw respectively. The rats were injected once per week for 6 weeks. Three days after the last injection, the rats were anesthetized using xylasin $(2 \mathrm{mg} / \mathrm{kg})$ and ketamine $(20 \mathrm{mg} / \mathrm{kg})$ intramuscularly, and then were intracardiac perfused using physiological saline as prerinse solution, followed by $10 \%$ buffered formalin solution as a fixative. After animals were fixed, the brains were removed and embedded in paraffin block and cut in $12 \mu \mathrm{m}$ thickness for immunohistochemistry staining using tyrosine hydroxylase antibody. The results of staining then were observed under light microscope and analyzed descriptively.

The results showed that the catecholaminergic neurons were distributed in the substantia nigra pars compacta in all treatment groups, however, the cell density were found decreased only in group IV. Catecholaminergic neurons appear in the bipolar and multipolar form, while dopamine 'Nigro striatal pathway' was found exist in all treatment groups. From our study, histologycally the decreased of catecholaminergic neurons is only found in rats that received paraquat dichloride in dose $15 \mathrm{mg} / \mathrm{kg}$ bw for 6 weeks.
\end{abstract}

Keywords: catecholaminergic neurons, paraquat dichloride, tyrosine hydroxylase, Parkinson's disease

\section{Introduction}

Parkinson's disease is a neurodegenerative disease that affects many elderly people due to the destruction of dopaminergic neurons in the substantia nigra (Uversky, 2004) or disruption of the

\section{*Corresponding author:}

Tri Wahyu Pangestiningsih, Department of Anatomy, Faculty of Veterinary Medicine, Gadjah Mada

University, Yogyakarta

Email : estifkh@ugm.ac.id
Nigro-striatal pathway that is the pathway of dopaminergic from the substantia nigra to the striatum (Betarbed et al, 2002). Previous studies have been conducted on the effects of paraquat dichloride in animal models is the toxic dose in rats ranged from 150-231 $\mathrm{mg} / \mathrm{kg}$, with a primary cause of death due to pulmonary damage (Gupta, 2007), the blood chemistry showed increased of creatinin, albumin and total bilirubun (Schober, 2004; Cicchetti, 2005). Tanner et al. (2011) reported that a Parkinson disease was associated 
with the expose of paraquat to the body that causes oxidative stress in mitochondria. This research used low doses of paraquat dichloride, but in a long periods treatment to describe how the farmers suffering Parkinson disease in the field. The succeed of Parkinson disease therapy is very low until now, due to many factors. To answer why this situation is happen, the investigation on many aspects of the Parkinson disease mechanism is very urgent to do, so the prevention can be done from the beginning. Recently research showed that any environmental influences such as the use of chemicals in agriculture, heavy metal exposure, and genetic factors, such as autosomal recessive juvenile, potential causing Parkinson disease (Uversky, 2005).

In daily activities, farmers often use herbicides to kill weeds that interfere with the productivity of the crops. Paraquat dichloride (1,1 dimethyl-4, 4 bipyridinum) is a phytotoxic herbicide, usually used to kill or inhibit the growth of grass (Gupta, 2007). Worldwide use of herbicides occurred during era of agriculture modernization almost reached $48 \%$ of total pesticide used. Such increasing is corespond with the changing of monoculture farming pattern and agricultural mechanization due to the increasing of the wages of the farmers. However, the use of herbicides in long period is threatening the farmer it self, and one of the potential disease causes by herbicides is Parkinson's disease (Betarbed et al, 2002).

Parkinson's disease is a neurodegenerative disease caused by the destruction of dopaminergic neurons in the substantia nigra pars compacta (Emborg, 2004). Dopamine is a neurotransmitter of catecholamine group, and synthesis of catecholamine is requires tyrosine hydroxylase enzyme (TH), hence the presence of these enzymes in the organs/tissues can be used as a marker of the presence of catecholaminergic cell (Reiner, 1994). Microscopic image of Parkinson's disease is characterized by the formation of Lewy bodies which are eosinophilic in the dopaminergic neurons(Uversky, 2004; Schober, 2004).
The aim of the research is to determine the effect of some low dose of paraquat dichloride to the histological changes of catecholaminergic neurons in the substantia nigra of Wistar rat's. Tyrosine hydroxylase antibody was used as the marker of catecholaminegic neurons in the substantia nigra using immunohistochemistry staining techniques. From this research we expect to find the saver dose and period in using paraquat dichloride as herbicide to avoid Parkinson's disease. According to Andreollo et al. (2012), every one day of rat is equal to 30 days of the man's life. Six weeks of paraquat dichloride treatment to the rat in this study is approximately equal to 3,5 years of human life.

\section{Materials And Methods Materials}

Twenty female Wistar rats (Rattus norvegicus Albinus), 3.5 months old were use as the animal model. Materials used to induce Parkinson's disease is paraquat dichloride (1,1 'dimethyl-4, 4'bipyridinium) diluted in aquabidest. The animals were euthanazed using Ketamine and xylasin, while perfusion were done using physiological saline and buffered formaldehyde. Materials used for histology and staining process were ethanol, xylol, paraffin, phosphate buffered Saline (PBS), blocking endogenous peroxidase, the primary antibody anti-TH mouse serum (Immunostar, Cat. No. 22941), and kit Startrek Universal HRP Detection (Biocare Medical, USA, Cat. No.STUHRP700 L10) that consist of blocking background material, secondary antibody, avidin-biotin, and chromogen 3,3-diaminobenzidine tetrahydrochloride (DAB). The equipment used were the infusion set, microtechnic set, light microscope with a digital camera.

\section{Methods \\ Perfusion and preparation of the brain samples}

Rats were divided into 4 groups, each group consisted of 5 animals. Group I was 
the control group injected with aquabidest, group II were injected with $5 \mathrm{mg} / \mathrm{kg}$ paraquat dichloride, group III (10 $\mathrm{mg} / \mathrm{kg})$, and group IV (15 mg/kg). Rats were injected intraperitonial once per week for 6 weeks.

Three days after the last injection, the rats were anaesthetized using combination xylasin $(2 \mathrm{mg} / \mathrm{kg})$ and ketamine $(20 \mathrm{mg} /$ $\mathrm{kg}$ ) by intramuscularly injection. During anasthesized condition, the rats were perfused intracardially using physiological saline as a pre-rinse. Intracardiac perfusion were done by flowing pre-rinse solution to the left ventricle and let it out from right atrium. The fixative solution (10\% buffered formalin) was flowed into the left ventricle following the pre-rinse after the pre-rinse solution that flow out from the right atrium was free from blood. The fixative solution was perfused until the whole body well fixed. Once the perfusion process completed, the brains were collected and fixed with $10 \%$ buffered formalin solution.

The brain was cut longitudinally in the mid line into two parts. The left side was cut in the coronal of mesensephalika flexure area with $5 \mathrm{~mm}$ thick, then were blocked using paraffin. The hemispheres then were stored for histological examination.

\section{The process of paraffin blocking and tissue sectioning}

Slices of brain were inserted into the tissue cassette, followed by dehydration process that carried out in serial solution of ethanol $70 \%, 80 \%, 95 \%$, and absolute ethanol for $60 \mathrm{~min}$ each at room temperature. Purification (clearing) process was conducted by mixing xylol and $100 \%$ ethanol solution, followed by xylol twice, for 45 minutes each at room temperature. Paraffin infiltration was conducted three times, for 45 minutes each, at $60^{\circ} \mathrm{C}$, then were embedded in paraffin, then cooled at room temperature.

Paraffin block were cutted in $12 \mu \mathrm{m}$ thick using a rotary microtome, then placed on the surface of warm water $\left(45^{\circ} \mathrm{C}\right)$ and placed on object glass that have been coated by gelatin and vertically drained. Glass object then placed on a slide warmer until well adhered.

\section{Immunohistochemical staining of tyrosine hydroxylase}

Slides of the tissue were arranged in racks and incubated at $60^{\circ} \mathrm{C}$ for 2 hours, then were cooled at room temperature. Tissue was deparaffined in xylol, three times 5 minutes each and continued by rehydration process in absolute alcohol, twice in 90\% alcohol, followed once in alcohol $80 \%$, alcohol $70 \%$, 5 minutes each. After that, the slides were dipped in distilled water for 10 dips, then washed three times in phosphate buffered saline (PBS), each for 5 minutes.

Endogenous peroxidase in the tissue was blocked by immersing slides in to $3 \%$ $\mathrm{H}_{2} \mathrm{O}_{2}$ for 30 minutes, then were rinsed three times in PBS, 10 minutes each. Surfaces around the slides were dried using tissue paper and keep the tissues moist. Slides then were aligned horizontally in a humid box, then tissue were spilled with Revealit Antigen solution and incubated at $37^{\circ} \mathrm{C}$ one night. Slides then were rinsed four times in PBS solution, 10 minutes each. Blocking background were done using a sniper for 15 min at room temperature.

Primary antibody Rat anti- tyrosine hydroxylase mouse serum $(1 / 2500)$ were applied to the adrenal tissue of the treatment groups, while the adrenal tissue of the control groups containing tyrosine hydroxylase were not treated with primary antibody. Slides then were placed horizontally in a humid box and incubate for 2 nights at $4^{\circ} \mathrm{C}$, then rinsed four times with PBS, for 15 minutes each. Furthermore, tissue was incubated at room temperature with a secondary antibody (Trekkie Universal Link) for 20 minutes, then rinsed three times using PBS, for 5 minutes each. Tissues were spilled with TrekAvidinHRP for 10 minutes and then were rinsed three times with PBS, 5 minutes each, then incubated with Betazoid DAB + substrate solution for 3 minutes. Tissues then were washed in distilled water for 10 dips and 
stained with hematoxylin for 1 minute as a counterstained. Finally, the tissues were dehydrated in alcohol, cleared in xylol, and coversliped using Canada balsam.

\section{Staining results}

The results of immunohistochemical staining of tyrosine hydroxylase based on the presence of catecholaminergic neurons Nigro-striatal pathway then were observed under microscope, and photographed by digital camera. Immunoreactived neurons were characterized by brownished yellow color of the cell. Three slides from each brain were observed for histology examination.

\section{Analysis of research results}

The images were processed with Adobe Photoshop 7.0 software and analyzed descriptively.

\section{Results and Discussion \\ Catecholaminergic neurons in the substantia nigra}

Based on the observation, we found that catecholaminergic neurons are distributed in the substantia nigra pars compactacompacta $(\mathrm{SNc})$ both of the treated rats group and the control group. Position of $\mathrm{SNc}$ is in the dorsal of substantia nigra pars reticulata $(\mathrm{SNr})$. Catecholaminergic neurons are immunoreactived neurons

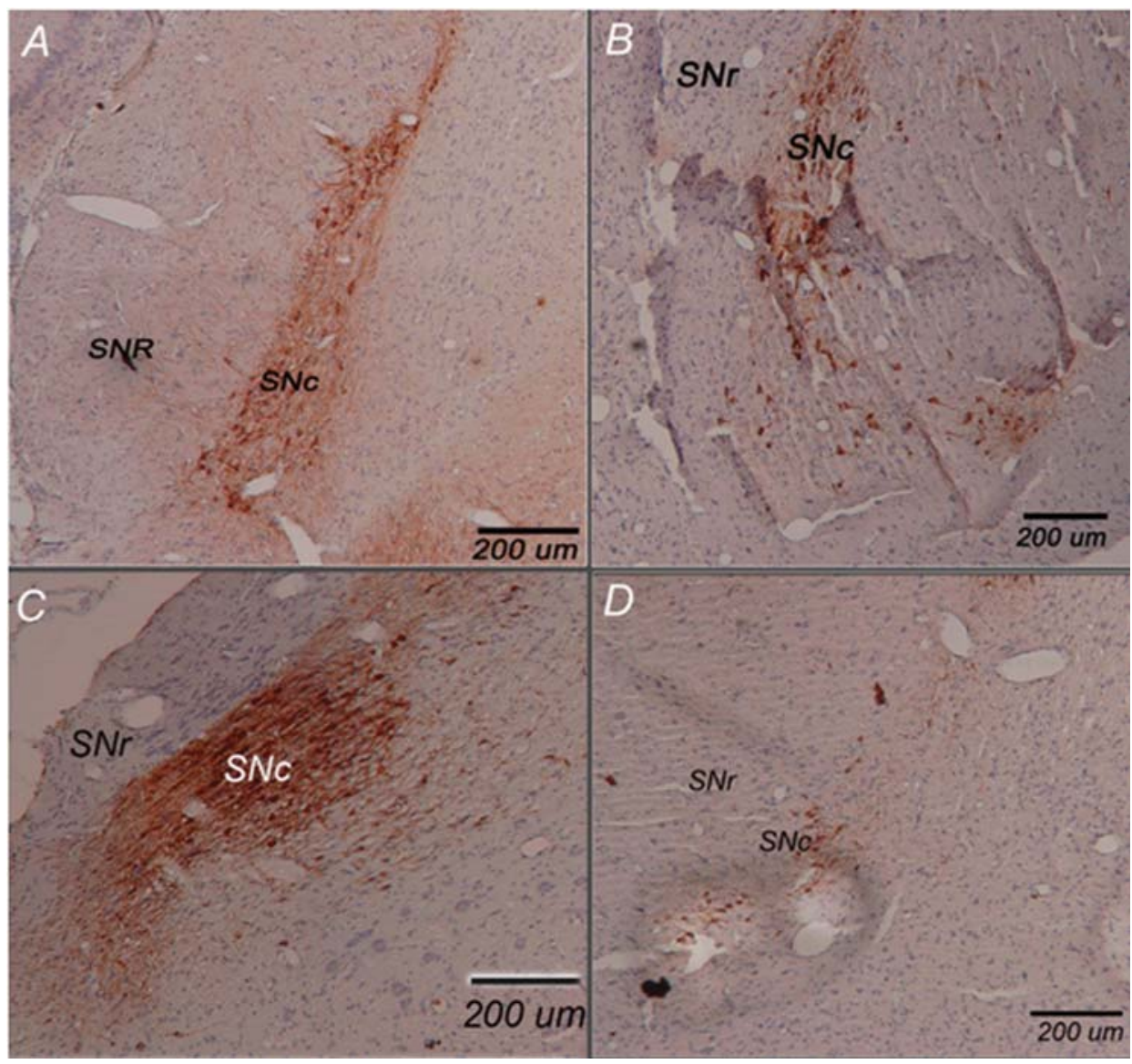

Figure 1. Catecholaminergic neurons in the substantia nigra pars compacta of rats after injected intraperitoneally with aquades, once a week for 6 weeks by tyrosine hydroxylase immunohistochemical staining. A. control's; B. dose $5 \mathrm{mg} / \mathrm{kg}$ bw's; C. dose $10 \mathrm{mg} / \mathrm{kg}$ bw's; D. dose $15 \mathrm{mg} / \mathrm{kg}$ bw's groups. Tyrosine hydroxylase immunoreactived neurons are catecholaminergic neurons, showed brown in color. SNc: substantia nigra pars compacta. SNr: substantia nigra pars reticulata. 


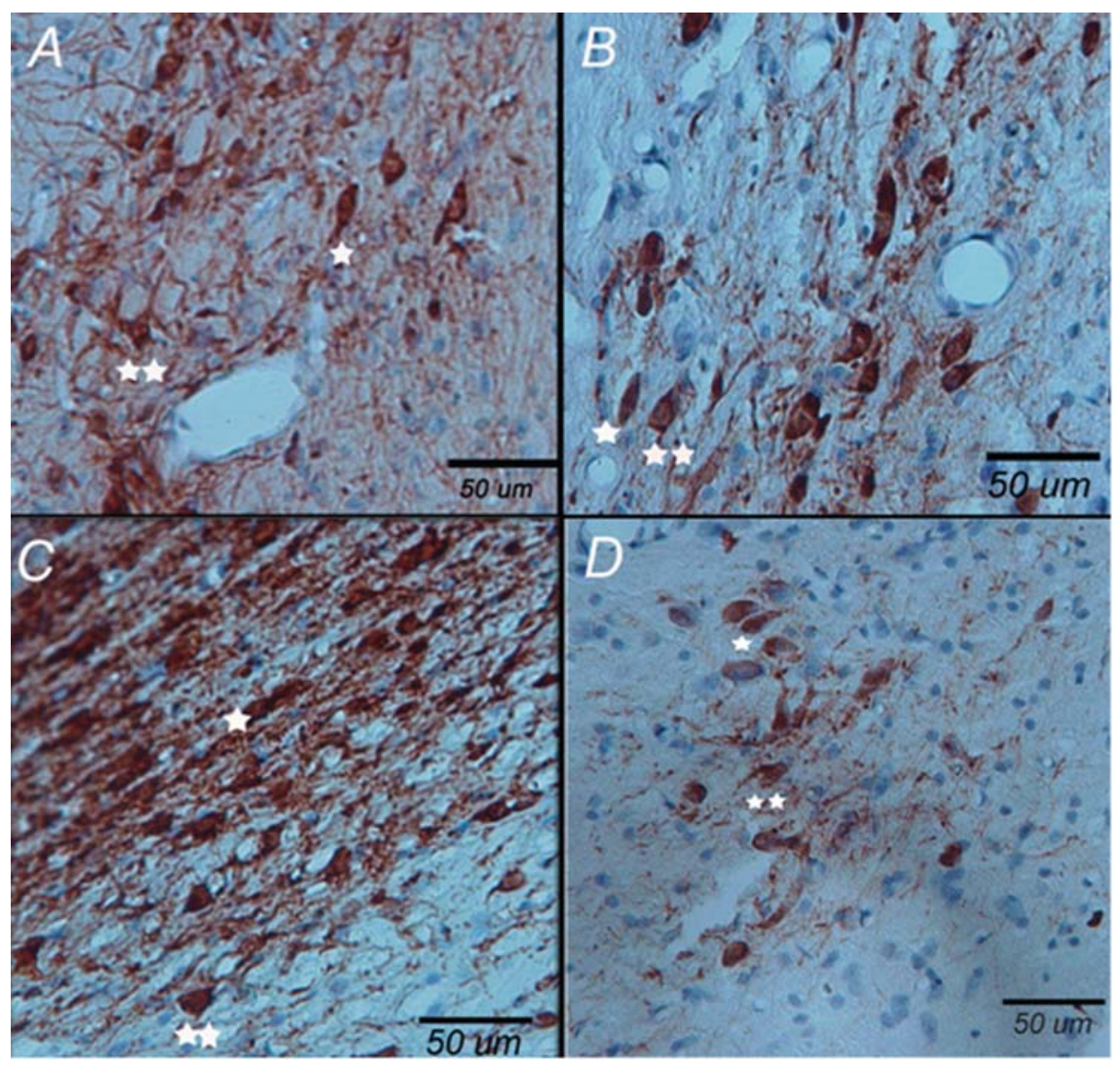

Figure 2. Type of catecholaminergic neurons in the substantia nigra pars compacta of rats after injected intraperitoneally with aquades, once a week for 6 weeks by tyrosine hydroxylase immunohistochemical staining. A. control's; B. dose $5 \mathrm{mg} / \mathrm{kg}$ bw's; C. dose $10 \mathrm{mg} / \mathrm{kg}$ bw's; D. dose $15 \mathrm{mg} / \mathrm{kg}$ bw's groups. Tyrosine hydroxylase immunoreactived neurons are catecholaminergic neurons, showed brown in color. Catecholaminergic neurons are bipolar $\left(^{*}\right)$ and multipolar $\left.{ }^{* *}\right)$ in shape. Figure D showed the decreased of neuronal denstity of catecholaminergic neurons compared with Figure A, B and C.

to tyrosine hydroxylase (TH) antibodies (TH) by immunohistochemical staining (Figure 1). Catecholaminergic neurons substantia nigra pars compacta are bipolar and multipolar in shape (Figure 2). The shape of Catecholaminergic neurons substantia nigra pars compacta in this research is similar with the shape of catecholaminergic neurons substantia nigra pars compacta of rhesus monkey that was reported by Felten and Sladek (1983).

Catecholaminergic neurons in rats of treament group that injected paraquat dichloride in dose $15 \mathrm{mg} / \mathrm{kg}$ bw were showed decrease in the cell densities compare with other groups, as shown in Figure 2D. The decrease in the cell densities are possibility the process of the cell death, as described by Bertabet (2002) is paraquat dichloride penetrate the blood-brain barrier, then metabolized into $\mathrm{MPP}^{+}$metabolites that toxic to mitochondria of dopaminergic neurons in the substantia nigra pars compacta and causing disruption of respiration cells and cellular oxidative stressed. According to Miller (2007) Paraquat can inhibit complex I of cell respiration process in mitochondria.

From the case-control study by Tanner $e t$ al. (2011) showed that Parkinson diseases are associated with paraquat. Their suggestion 


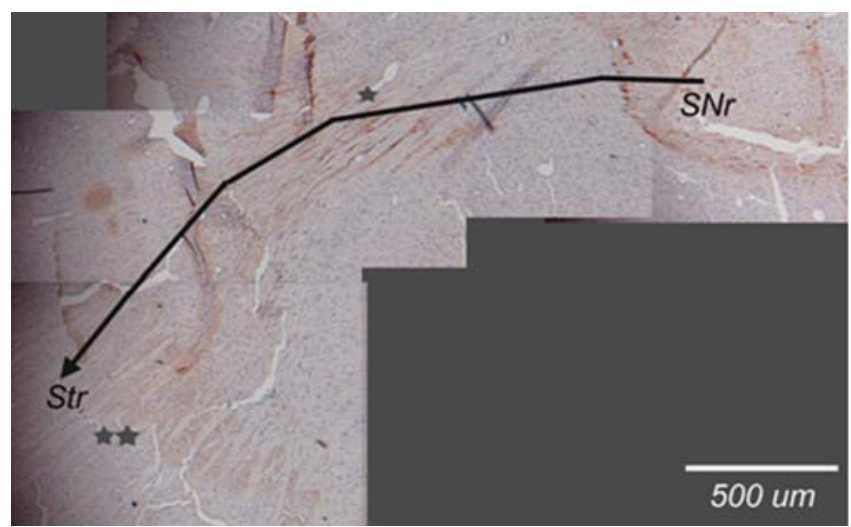

Figure 3. Nigro-striatal pathway expand from the substantia nigra pars compacta (SNc) to the striatum (Str) in the rats who injected with $5 \mathrm{mg} / \mathrm{kg}$ BW paraquat dichloride intraperitoneally, once a week for 6 weeks, arrows indicating Catecholamines is carried by axons $\left(^{*}\right)$ to the axon terminal $\left({ }^{* *}\right)$.

is paraquat increases production of certain oxygen derivate that may harm cell structure. In this research it is likely, some cells unable to overcome with oxidative stress that caused cell death. Further research needs to investigate the occurrence of oxidative stress by using its specific marker.

Based on the clinical symptoms, treated rats did not showed the typical signs of Parkinson's disease such as tremor, rigidity, and difficulty moving. It is likely, the cell damaged that occured is still able to be overcome by the body.

\section{The existence of Nigro-striatal pathway}

The dopamine pathway is expand from the substantia nigra pars compacta heading into the striatum, called Nigro-striatal pathway as found on the treated groups. This pathway begins with catecholaminergic neuron cell bodies that produce dopamine in the substantia nigra pars compacta, then carried by the axon toward the axon terminals in the striatum, as shown in Figure 3. Rats that received paraquat dichloride in dose $15 \mathrm{mg}$ / $\mathrm{kg}$ bw showed the axon and axon terminal that immunoreactive to tyrosine hydroxylase antiboby (Figure 4) which is indicated that Nigro-striatal pathway exist in this group. The existence of Nigro-striatal pathway showed that the dopamine system has been working properly so that the animals did not suffered of rigidity although the group of rats that received paraquat dichloride in dose $15 \mathrm{mg} /$ $\mathrm{kg}$ showed weaker body condition compare with other groups.

Parkinson's disease characterized by distruption of dopamine production in substantia nigra pars compacta or alteration of Nigro-striatal pathway and showed the clinical sign such as as tremor, bradykinesia, hypokinesia, balance and movement disorders (Paxinos, 2004; Betarbed et al, 2002; Emborg, 2004).

The results of this study showed that although the rats did not showed symptoms of Parkinson's disease and Nigro-striatal pathway is remain exist, but there is a decreased of neuronal density of catecholaminergic neurons in the substantia nigra pars compacta in the rats that reveived paraquat dichloride in dose $15 \mathrm{mg} / \mathrm{kg}$ bw. Based on this results, it is hypothetized that dose $15 \mathrm{mg} / \mathrm{kg}$ bw of paraquat dichloride treatment period caused neuronal changes of catecholaminergic neurons in the substantia nigra pars compacta and its potentially leading to Parkinson's disease.

\section{Conclusions}

From our study, histologycally the decreased neuronal density of catecholaminergic neurons in substantia nigra pars compacta is only found in rats that 

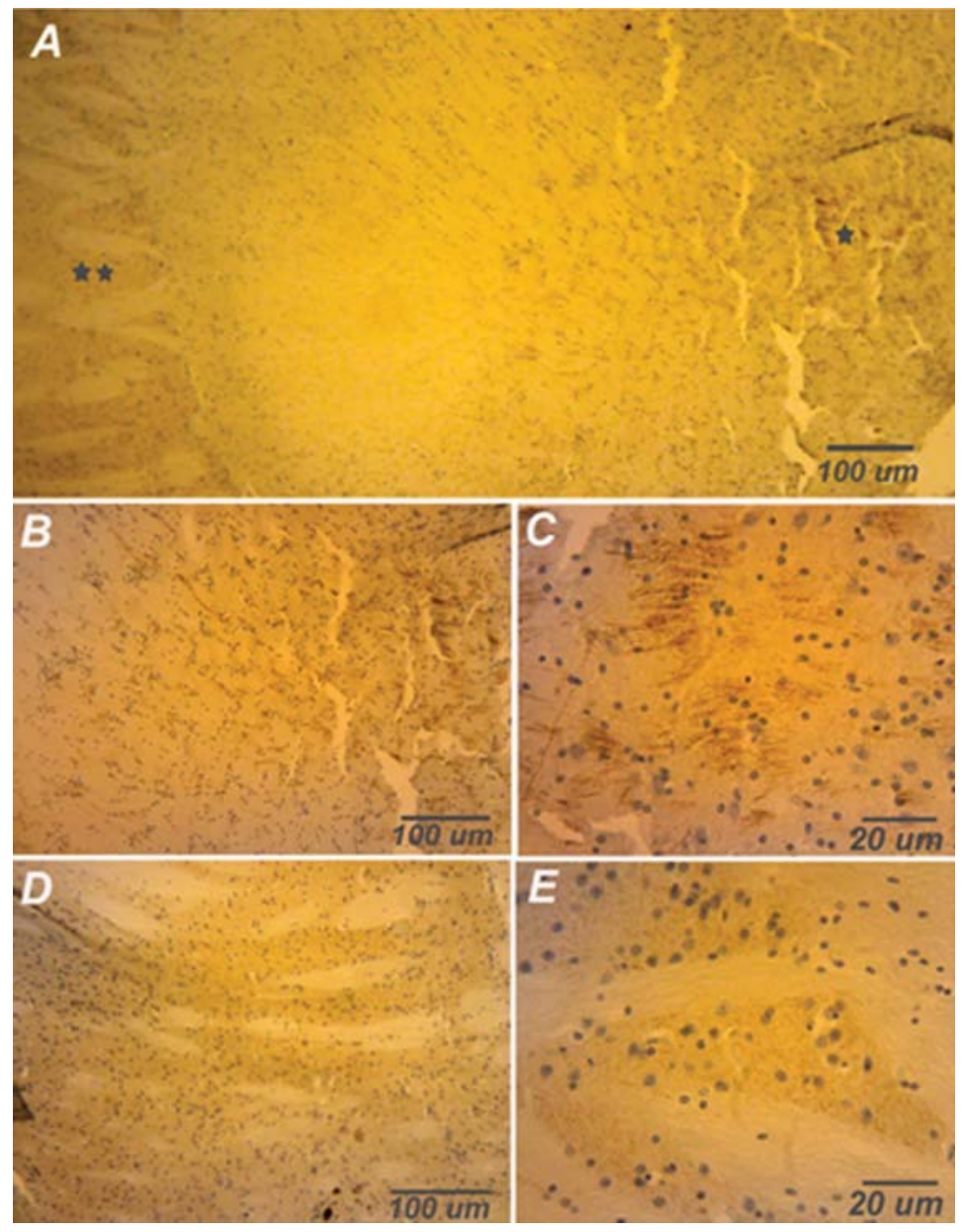

Figure 4. Axon and axon terminal of tyrosine hydroxylase immunoreactive tissue in the striatum of the rats who injected with $5 \mathrm{mg} / \mathrm{kg}$ BW paraquat dichloride intraperitoneally, once a week for 6 weeks. A. One star indicating catecholamines in the axons and two stars indicating catecholamines in the axon terminal of striatum. B and C are higher magnification of axon (one star area) that immunoreactive to tyrosine hydroxylase. D and E are higher magnification of axon terminal in the striatum (two stars area) that immunoreactive to tyrosine hydroxylase.

received paraquat dichloride in dose $15 \mathrm{mg} /$ $\mathrm{kg}$ bw for 6 weeks.

\section{Acknowledgement}

We would like to thanks to the Dean of Faculty of Veterinary Medicine, GadjahMada University for any support of this research.

\section{References}

Andreollo, N. A., dos Santos, E. F., Araújo, M. R., and Lopes, L.R. 2012. Review Article: Rat's Age Versus Human's Age: What Is The Relationship? ABCD Arq Bras Cir Dig. 25(1), 49 - 51
Betarbet, R., Sherer, T. B. and Greenamyre, J. T., 2002. Animal models of Parkinson's: Review articles. BioEssays. Wiley Periodicals., 24,308-318.

Cicchetti, F., 2005. Systemic exposure to paraquat and maneb models early Parkinson's disease in young adult rats. Neurobiology of Disease. Elsevier Inc., 20, 360-371.

Emborg, M. E., 2004. Evaluation of animal models of Parkinson's disease for neuroprotective strategies. Journal of Neuroscience Methods., 139, 121-143.

Felten DL, Sladek JR. 1983. Monoamine distribution in primate brain $\mathrm{V}$. 
Pangestiningsih et al.

Monoaminergic nuclei: anatomy, pathways and local organization. Brain Res Bull, 10: 171-284

Gupta, R. S., (2007) Veterinary Toxicology: Basic and Clinical Principles. KentuckyUSA. Elsevier Publ.

Hau. J. and Van Hoosier G. L., (2005) Handbook of Laboratory Animal Science Second Edition. Volume III Animals Models. New York.: GRC Press.

Iddo M. and Chesselet M. F., 2010. Genetic mouse models of Parkinson's disease: The state of the art. Progress in Brain Research, Vol. 184(2). 53-87

Kiernan JA. (2008) Histological and Histochemical Methods: Theory and practice, $4^{\text {th }}$ ed. Bloxham, UK: Sction.

Paxinos.G. (2004) The Rat Nervous System. Third Edition. Elsevier Academic Press. Sydney. Australia.

Miller, G.W. 2007. Editorial. Paraquat: The Red herring of Parkinson Disease Research. Toxicol. Sci. 100(1), 1-2

Reiner A. (1994) The study of catecholaminergic perikarya and fibers in the nervous system: methodological considerations and technical limitations, in Phylogeny development of catecholamine systems in the CNS of Vertebrate, editor Smeets WJ, Reiner A, Cambridge, Cambridge University Press.

Uversky, V N. 2004. Neurotoxicant-induced animal models of Parkinson's disease: understanding the role of rotenone, maneb and paraquat in neurodegeneration. Cell tissue Res. Springer-Verlag. 318, 225-241.

Schober, A. 2004. Classic toxin-induced animal models of Parkinson's disease: 6-OHDA and MPTP. Cell Tissue Res. Springer-Verlag. 318 (1), 215-24

TannerC.M, KamelF., Ross, G.W.,Hoppin,J.A., Goldman,S.M., Monica Korell M., ${ }^{1}$ Marras C., , ${ }^{4}$ Bhudhikanok,G.S., Kasten,M., Chade AR., Comyns, K., ${ }^{1}$ Richards,M.B., Meng,C., Priestley,B., Fernandez,H.H., Cambi,F., .Umbach, D.M., Blair,A., Sandler,D.P., and Langston,
I.J. Biotech.

J.W. 2011. Rotenone, Paraquat, and Parkinson's Disease. Environ Health Perspect. 119(6), 866-872 